\title{
Obituary
}

Korean J Transplant 2020;34:217-218

https://doi.org/10.4285/kjt.20.201218

pISSN 2671-8790

eISSN 2671-8804

\section{In memory of Yong Bok Koh}

\author{
In Sung Moon
}

Professor Emeritus, Department of Surgery, College of Medicine, The Catholic University of Korea, Seoul, Korea

Professor Yong Bok Koh, one of the great surgeons at the College of Medicine of the Catholic University of Korea, passed away early in the morning of October 30, 2020, at the age of 80 years (Fig. 1). He had suffered from back pain-he had previously undergone a couple of lumbar surgeries and cervical spine surgery-and coronary heart problems, for which he had a coronary artery stent.

He graduated from College of Medicine of The Catholic University of Korea in 1966, after which he finished his surgical residency in 1971 from the Catholic Medical Center. He served as a medical officer in Navy from 1971 to 1974. He then joined the surgical staff as an Instructor of Surgery at St. Mary's Hospital with his passion for vascular and transplantation surgery during his life's work as a surgeon. He also underwent residency training at the Department of Vascular Surgery in New York University under the instruction of Professor Frank Spencer. From then on, he has paved the way for vascular and transplantation surgery at the Catholic University Medical Center.

In the field of vascular surgery, he did pioneering work involving experimental microvascular skills and techniques in rats. On Saturday afternoons, after working hours, he used to perform animal experiments with rats in the hospital corridor. He usually experimented with kidney transplantation, heart transplantation, and aortic aneurysm model surgery. He always had a surgical resident assist him with administering anesthesia during this operation. The surgical resident's mission was to perform the open drop method of ether anesthesia into the nose of the rat. If the rat stopped breathing from deep anesthesia, it was the resident's role to perform cardiopulmonary resuscitation (CPR; all the residents who trained at the Department of Surgery in Catholic University Hospital have mastered rat $\mathrm{CPR}$ ). Being almost anesthetized by the ether, the constantly tired surgical residents almost always fall asleep. I remember the times I fell asleep during the experiment and was seriously scolded.

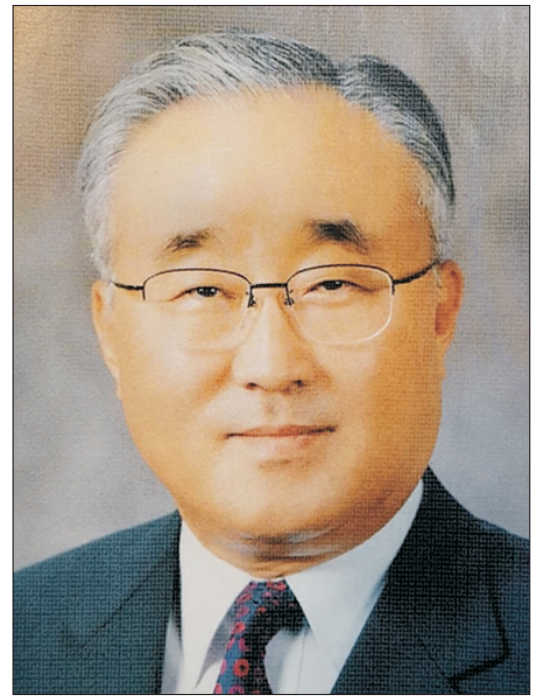

Fig. 1. Professor Yong Bok Koh (February 2,1941-October 30, 2020). 
Professor Koh performed all arterial bypass surgeries from the thoracic aorta to the dorsalis pedis artery and also new surgical techniques, such as the Taylor patch and Miller collar, almost every day. He also performed the operation for Budd-Chiari syndrome, Palma Dale operation, Linton's perforator ligation operation, and iliofemoral thrombectomy with temporary arteriovenous fistula operation for vein surgery on a daily basis, in addition to non-vascular surgeries such as lumbar sympathectomy and cervical sympathectomy. Performing countless surgeries almost every day, he was free from the operation rooms only during outpatient appointments on Tuesday and Friday mornings. There were times when he could not even make it to those appointments due to occasional emergency surgeries.

Professor Koh's passion and his strength in the operating room were unmatched. We used to call him "a man with two hearts"-one heart being the normal heart that we all have and the other heart for performing operations. He used to listen to calm music such as "Life is incomplete" by Jin-kwan Lee and Hee-joon Choi's "Life is a traveler's path" during the long hours of surgery. I remember us assistants listening to these two songs tirelessly while assisting him in the operating room. Professor Koh also made great professional contributions to the field of transplantation. As one of the first members to successfully perform liver transplantation at the College of Medicine of the Catholic University of Korea, he further focused on kidney transplantation. Of course, this was after he laid the foundation for basic animal testing at the College of Medicine of the Catholic University of Korea by passing microvascular surgery techniques established in rats. As the first attending physician during the first kidney transplant surgery performed in 1969 during his 3rd year of residency, Professor Koh continued to engage in kidney transplantation until his retirement in 2006. $\mathrm{He}$ is considered a historical figure in the field of kidney transplantation at the College of Medicine of the Catholic University of Korea. In the 1980s and 1990s, he took the lead in the clinical application of newly discovered new immunosuppressants, such as cyclosporine and tacrolimus, as a member of the Korean research team. He also led 1,500 cases of kidney transplantation at the Catholic Medical School until his retirement. I am also well aware of Professor Koh's Catholic faith as he had always attended Mass every Wednesday during lunch, and he prayed at the chapel every morning before work. It is well known that many patients with end-stage renal disease have undergone transplants and are living a new life.

Professor Koh, who worked hard for many patients and trained many students, passed away comfortably and painlessly on the morning of October 30,2020. Professor Koh was buried beside his father in peace. In the bus on my way from Professor Koh's grave, I was in deep sorrow while listening to "Life is incomplete" by Jin-kwan Lee, with the thought that Professor Koh will not be able to hear this song ever again. On behalf of all members of the College of Medicine of The Catholic University of Korea, the Korean Society for Transplantation, and the Korean Society for Vascular Biology and Medicine, I leave, with grief, a message of condolence. 